\title{
Production of shape memory thin strips by twin roll casting technique
}

\author{
F. Dalle ${ }^{1}$, C. Elgoyhen ${ }^{1}$, G. Despert ${ }^{1}$, J. Malaria ${ }^{1}$, R. Portier ${ }^{1,2}$, A. Dezellus ${ }^{2}$, \\ P. Plaindoux ${ }^{2}$ and P. Ochin ${ }^{2}$ \\ ${ }^{1}$ Laboratoire de Métallurgie Structurale, École Nationale Supérieure de Chimie de Paris, \\ 11 rue Pierre et Marie Curie, 75231 Paris cedex 5, France \\ ${ }^{2}$ Centre d'Études de Chimie Métallurgique, CNRS, 15 rue Georges Urbain, \\ 94407 Vitry-sur-Seine cedex, France
}

\begin{abstract}
Rapid solidification techniques were first used to obtain amorphous or microcrystalline metallic materials, which required high quenching rates $\left(10^{4}-10^{6} \mathrm{~K} \cdot \mathrm{s}^{-1}\right)$. Applied to shape memory alloys, the twin roll casting technique allows semi-finished materials (strips) with reduced grain size to be obtained. This is particularly useful for certains shape memory alloys for which shaping is difficult because of their inherent lack of ductility. The melt is cast through a nozzle and solidified between the gap of two rollers rotating in opposite directions. Optimum conditions must be established to obtain thin foils with a smooth surface, not brittle and free of cracks and holes. It is only possible for a limited combination of the following experimental parameters : roll speed, melt temperature, melt flow, ejection pressure and roll gap. In this work, we have characterized (transformation temperatures, microstructures) copper based and Ni-Ti-Hf strips, with a thickness between 150 and $500 \mu \mathrm{m}$. For copper based alloys, it has been found that transformation temperatures were in a similar range to those of conventionnally cast alloys, which is not the case of melt spun ribbons whose transformation temperatures dramatically decrease. For NiTi-Hf strips cast with different conditions, transformation temperatures vary : some are close to the conventionnally solidified material but some others are lower.
\end{abstract}

\section{INTRODUCTION}

Technologies for producing thin sheets of alloys directly from the molten state received a lot of attention because with such direct casting techniques, it is not only possible to make savings in further processing but also to obtain new material properties. This is achieved by a higher rate of solidification than is possible in conventional ingot casting, and by the subsequent rapid cooling. Because it is possible to reduce embrittlement by rapid cooling during the casting of thin strips, this process represents a major success. The Twin Roll Casting (or quenching) technique [1,2] has been used for aluminium and is still under development for high silicon steel, stainless and carbon steels strips production $[3,4,5]$. Intermetallic compounds and generally hard to roll materials are also concerned. Thin sheets of metal, some hundreds of micrometers to some millimeters thick, can be produced according to experimental conditions and especially the roll diameter [5]. Rapid solidification techniques, based on chill block melt spinning, have been used recently to prepare shape memory ribbons $20-60 \mathrm{~mm}$ thick, and subsequent improvement of the ductility has been demonstrated [6]. Unfortunately transformation temperatures for those ribbons are largely shifted towards lower temperatures than those of bulk materials. This distinctive feature led us to use the twin-roll casting method for the production of shape memory thin foils (copper based and Ni-Ti-Hf) for which shaping, by conventional techniques, is difficult because of their lack of ductility. Strips, 150 to $500 \mu \mathrm{m}$ thick, have been prepared and characterized.

\section{EXPERIMENTAL PROCEDURES}

The temperatures, hysteresis and enthalpies of transformations were determined by DSC using a Mettler DSC 30 apparatus. The scanning rate was $15 \mathrm{~K} / \mathrm{min}$ for copper based alloys and $20 \mathrm{~K} / \mathrm{min}$ for Ni-Ti-Hf alloys. For TEM observations of copper based alloys, the $3 \mathrm{~mm}$ diameter double roller and bulk discs were mechanically ground and polished to a thickness of $150 \mu \mathrm{m}$. The discs were then thinned with a 
double jet electro-polishing $\mathrm{HNO}_{3}-\mathrm{CH}_{3} \mathrm{OH}$ solution (1/3). The conditions were : a temperature of $233 \mathrm{~K}$, a voltage of $10 \mathrm{~V}$, an electrolyte flux rate of $4 \mathrm{AU}$. The thin foils were examined with a JEOL $-2000 \mathrm{FX}$ transmission electron microscope operating at $200 \mathrm{kV}$. Optical observations of Ni-Ti-Hf thin strips were carried out after etching in a $50 \mathrm{ml} \mathrm{H}_{2} \mathrm{O}_{2}-12 \mathrm{ml} \mathrm{HNO}_{3}-2 \mathrm{ml} \mathrm{HF}$ solution.

\section{TWIN ROLL CASTING TECHNIQUE}

The twin roll process involves two operations : solidification of a liquid layer on a rotating substrate above a so-called solidification end point, and hot-rolling of the solidified shells below the solidification end point (fig. 1). Solidification has to be completed prior to exiting from the rollers and as a result strips should exhibit considerable deformation. The foil formation is complex and controlled by the interaction of both fluid and heat flow, thus the process cannot be described by any single mechanism [7]. The high solidification and cooling rates $\left(10^{4}\right.$ to $\left.10^{5} \mathrm{~K} / \mathrm{s}\right)$ give reason to expect that the microstructure be extremely low segregated. Meanwhile the formation of a solid sheet with plane surface is only possible for a limited combination of different experimental parameters.

\subsection{Description}

The process involves rolling of a melt stream between two conducting rolls, $400 \mathrm{~mm}$ diameter, composed of two aluminium cylinders with $1 \mathrm{~cm}$ thick copper rim, rotating in opposite directions. The gap between the rolls is adjusted with calibrated wedges.

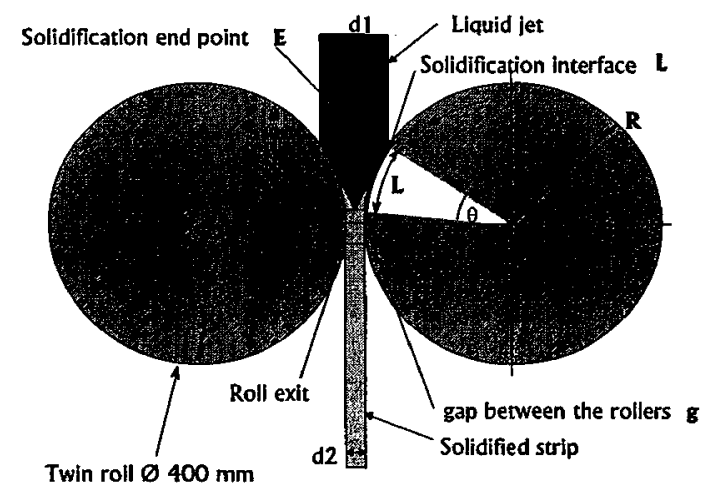

Figure 1 : Twin-roll casting principle

Each alloy (15 to $40 \mathrm{~g}$ ) is placed in quartz nozzles with holes going from 1,5 to $2,5 \mathrm{~mm}$ diameter. The ingots are induction-melted with a RF generator $(50 \mathrm{~kW})$ in a chamber which has been pre-evacuated prior to filling with a one bar helium atmosphere. The melting temperature is controlled with an IR pyrometer. The melt temperature is fixed 50 to $150^{\circ} \mathrm{C}$ above the liquidus temperature according to the viscosity of the melt. The melt ejection is under the control of a boron nitride shutter, closing the nozzle tip, which is triggered by an electro-magnet. The melt is ejected downward (with a pressure of argon) into the nip of the rolls. By controlling carefully different parameters of the experiment, it is possible to produce thin foils in a range $150 \mu \mathrm{m}-500 \mu \mathrm{m}$ from the melted alloy (tables 1,4 ).

When the metal jet contacts the rotating substrate, a pool is created. Metal layers simultaneously solidify on each roll and converge together as they approach the nip region. The remaining unsolidified liquid from the central pool is forced to spread laterally outward contributing to the final foil [7]. Conductive cooling into the rollers primarily controls the solidification. The resulting strip emerges from the nip and detaches from the rollers. The thickness of the primary solidified layer is a function of the contact time with the roll surface, while the overwhole thickness is partially controlled by the roll-gap. Mass-flow rate and jet velocity are a function of ejection pressure while the former is also proportionnal 
to the jet diameter (nozzle hole). It is assumed that no break-up of the jet occurs during its free travel. For continuous foil formation the angular velocity and jet velocity are to be coupled in a proper ratio.

\subsection{Sensitive variables governing the process}

Application of the twin roll process is difficult due to the precise control of casting conditions such as feeding rate, melt temperature, casting speed, pool level of the melt.

The solidification end point (fig. 1) is an important parameter which has an influence on strip forming $[7,8]$. The location of the solidification end point and the temperature elevation of the roll greatly depend on the roll speed. High speed makes moving the solidification end point to near the roll exit. Slow angular velocity makes the rolling force increase by means of the solidification end point being far from the roll exit. The slower angular velocities are, the higher the elevation of roll temperature and rolling force are. If the solidification end point is located at too upstream from rolling exit, the solid-liquid interfaces come in contact with each other prior entering the nip region and rolling ratio becomes large. Because of the sever deformation expected, the strip may have a non-uniform thickness in width direction; thus the foil is potentially thicker than the roll-gap. If the solidification end point is located at too down-stream from roll exit, the two solidified shells are not bonded so that it goes out from roll exit in partially molten state. At the nip section, the primary solidified layers should be thick enough to contain the remaining liquid within the cross-section of the foil. The remnant liquid will solidify by convection and radiation at a lower cooling rate $\left(<10^{3} \mathrm{~K} / \mathrm{s}\right)$. When the solid-liquid interfaces join right into the nip, the final thickness will be closed to the roll-gap. Therefore the solidification end point which acts on strip forming determinantly, is presented as a function of revolution roll, roll nip gap, pouring temperature etc. Some examples experienced in our laboratory are given, which concern the preparation of thin strips of shape memory alloys (copper and $\mathrm{Ni}-\mathrm{Ti}-\mathrm{Hf}$ ) with $400 \mathrm{~mm}$ diameter rolls.

\section{EXAMPLES OF THIN STRIPS CHARACTERIZATION}

\subsection{Copper-based shape memory thin strips}

In this part a comparison between microstructure and martensitic tranformation in bulk, strips and ribbons copper based alloys is presented.

\subsubsection{Samples preparation parameters - dimensions}

The experimental parameters of elaboration for the $\mathrm{Cu}_{86-\mathrm{x}} \mathrm{Al}_{13} \mathrm{Ni}_{\mathrm{x}} \mathrm{Ti}_{1}$ alloys $(\mathrm{x}=4.5,5,5.5,6)$ and the dimensions of the obtained materials are presented in table 1.

Table 1 : sample preparation parameters and dimensions of $\mathrm{Cu}_{86-x} \mathrm{Al}_{13} \mathrm{Ni}_{x} \mathrm{Ti}_{1}$ alloys ( $\mathrm{SR}=$ Single Roller; $\mathrm{DR}=\mathrm{Double} \mathrm{Roller}$ )

\begin{tabular}{|c|c|c|c|c|c|}
\hline & SR & DR & & SR & DR \\
\hline wheel material & Cu(Co-Be) & copper & Wheel rate $(\mathrm{m} / \mathrm{s})$ & 19 & 0.6 \\
\hline distance nozzle-wheel $(\mathrm{mm})$ & contact & 80 & Dimensions & Ribbons & Strips \\
\hline superheating temperature & $1300^{\circ} \mathrm{C}$ & $1300^{\circ} \mathrm{C}$ & Width $(\mathrm{mm})$ & $8-9$ & $10-40$ \\
\hline ejection pression (mbars) & 250 & 250 & Thickness $(\mu \mathrm{m})$ & $55-80$ & $350-550$ \\
\hline
\end{tabular}

\subsubsection{Thermal analysis}

Table 2 presents the results of the calorimetric measurements after the stabilisation of transformation temperatures for the annealed bulk specimens and the as-quenched strips and ribbons. These temperatures are reproducible from the second cycle (fig. 2).

We have plotted the evolution of $\mathrm{Ap} 2$ and $\mathrm{Mp} 2$ with the nickel content for the bulk and rapidly solidified alloys (fig. 3a, b). It clearly appears that Ap2 and $\mathrm{Mp} 2$ temperatures of single roller melt spun alloys are lower that those of corresponding bulk alloys. A decrease of about $100 \mathrm{~K}$ is obtained for the $\mathrm{Mp}$ value of the $6 \% \mathrm{Ni}$ ribbon compared to the bulk specimen. On the contrary, the transformation 
temperatures of the strips are in the same range of temperatures to those of the corresponding bulk alloys. The Ap value of strips are even higher.

Table 2 : Transition temperatures of the bulk, single roller and double roller melt spun $\mathrm{Cu}_{86-\mathrm{x}} \mathrm{Al}_{13} \mathrm{Ni}_{\mathbf{x}} \mathrm{Ti}_{1}$ alloys (ribbon and strip)

\begin{tabular}{|l|l|l|l|l|l|l|l|l|}
\cline { 2 - 9 } \multicolumn{1}{c|}{} & \multicolumn{2}{l|}{4.5} & \multicolumn{2}{l|}{5} & \multicolumn{2}{l|}{5.5} & \multicolumn{2}{l|}{} \\
\cline { 2 - 9 } \multicolumn{1}{c|}{} & Ap2 & Mp2 & Ap2 & Mp2 & Ap2 & Mp2 & Ap2 & Mp2 \\
\hline Bulk & 216 & 184 & 112 & 65 & 118 & 95 & 137 & 115 \\
\hline DR & 250 & 205 & 120 & 60 & 121 & 62 & 144 & 112 \\
\hline SR & 188 & 121 & 34 & -14 & 16 & -26 & 53 & 6 \\
\hline
\end{tabular}

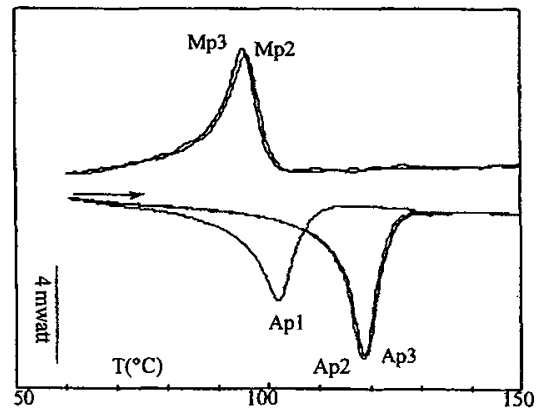

Figure 2 : Thermogram of the annealed bulk $\mathrm{Cu}_{86 \cdot \mathrm{x}} \mathrm{Al}_{13} \mathrm{Ni}_{\mathrm{x}} \mathrm{Ti}_{1}$ alloy with $5.5 \% \mathrm{Ni}$

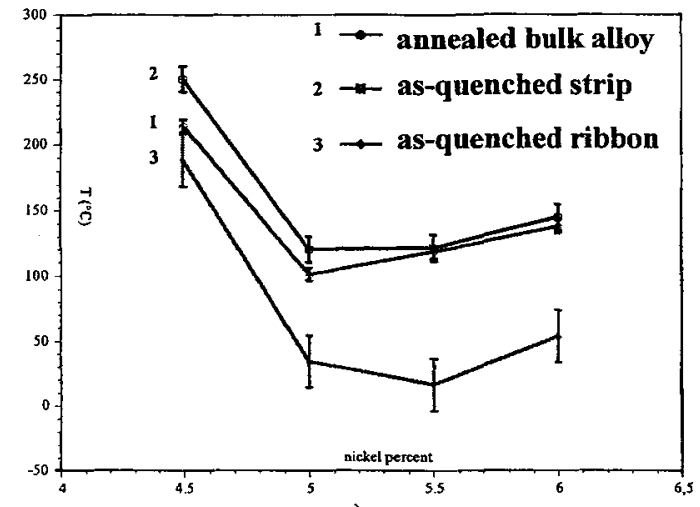

a)

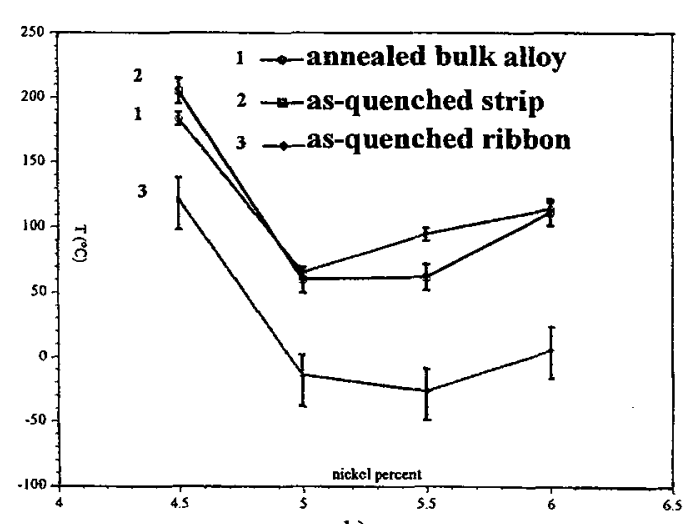

b)

Figure 3 : Evolution of transition temperatures, a) $\mathrm{Ap} 2$, b) $\mathrm{Mp} 2$, for $\mathrm{Cu}_{86-\mathrm{x}} \mathrm{Al}_{13} \mathrm{Ni}_{\mathrm{x}} \mathrm{Ti}_{1}$ bulk, strip and ribbon

\subsubsection{Microstructure}

We have correlated this thermal behaviour with electron microscopy investigations. We only present in this paper the results concerning the $5.5 \% \mathrm{Ni}$ alloy. A considerably reduced grain size is noted for the ribbon compared to the corresponding bulk. Concerning the strip and the bulk specimen, a similar size of the components of the microstructure (plates of martensite) is observed (fig. 4a, b, c).

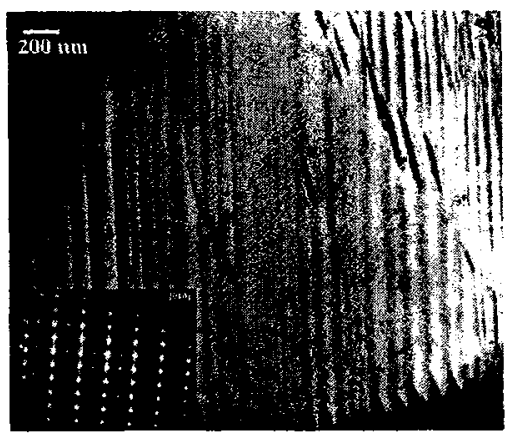

a)

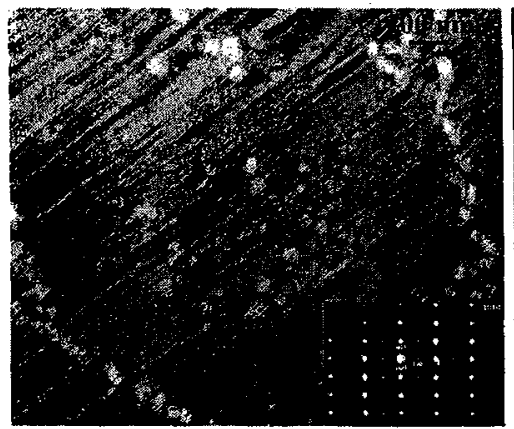

b)

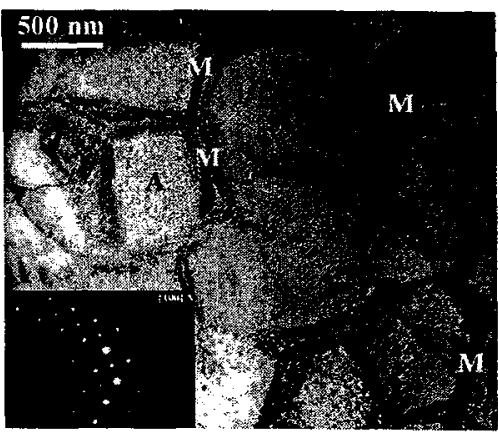

c)

Figure 4 : BF images and SAED patterns of the a) annealed bulk specimen, b) as-quenched strip, c) as-quenched ribbon $\left(\mathrm{Cu}_{80.5} \mathrm{Al}_{13} \mathrm{Ni}_{5.5} \mathrm{Ti}_{1}\right.$ alloy) 
Table 3 : Microstructure of bulk alloy, single roller and double roller melt spun $\mathrm{Cu}_{80.5} \mathrm{Al}_{13} \mathrm{Ni}_{5.5} \mathrm{Ti}_{1}$ alloy (ribbon and strip)

\begin{tabular}{|c|c|c|}
\hline BULK & DR & SR \\
\hline $\begin{array}{c}\text { A 2H martensitic structure with a XI } \\
\text { precipitation }\end{array}$ & $\begin{array}{c}\text { A 2H martensitic structure with } \\
\text { cellular decoration of XI precipitates } \\
\text { width }: 50-100 \mathrm{~nm} \text {, length }: 10 \mu \mathrm{m}, \\
\text { Width : } 500-700 \mathrm{~nm} \text {, length : 10-15 } \mu \mathrm{m}\end{array}$ & $\begin{array}{c}\text { An austenitic cellular microstructure, } \\
\text { the cells walls being formed by } \\
\text { martensite platelets }\end{array}$ \\
$\phi X 1: 4-5 \mu \mathrm{m}$ & $\phi X 1: 50-100 \mathrm{~nm}$ & $\phi g r a i n: 2-3 \mu \mathrm{m}, \phi \mathrm{cell}: 200-300 \mathrm{~nm}$ \\
\hline
\end{tabular}

\subsection{Nickel-titanium-hafnium shape memory thin strips}

\subsubsection{Samples preparation parameters - dimensions}

Table 4 shows some of the preparation parameters used to produce seven $\mathrm{Ni}_{49.8} \mathrm{Ti}_{42.2} \mathrm{Hf}_{8}$ foils from bulk material. The ejection pressure was fixed at 250 mbar and the nozzle tip - roll nip distance at $80 \mathrm{~mm}$.

Table 4 : Sample preparation parameters and dimensions of $\mathrm{Ni}_{49.8} \mathrm{Ti}_{42.2} \mathrm{Hf}_{8}$ ribbons

\begin{tabular}{llllllll}
\hline Ribbon & $\begin{array}{l}\text { Melt temperature } \\
\left({ }^{\circ} \mathrm{C}\right)\end{array}$ & $\begin{array}{l}\text { Nozzle hole } \\
(\mathrm{mm})\end{array}$ & $\begin{array}{l}\text { Rollers speed } \\
\left(\mathrm{m} . \mathrm{s}^{-1}\right)\end{array}$ & $\begin{array}{l}\text { Rollers gap } \\
(\mu \mathrm{m})\end{array}$ & $\begin{array}{l}\text { Ribbon } \\
\text { width }^{*}(\mathrm{~cm})\end{array}$ & $\begin{array}{l}\text { Center thickness } \\
(\mathrm{mm})\end{array}$ & $\begin{array}{l}\text { Edge thickness } \\
(\mathrm{mm})\end{array}$ \\
\hline 1 & 1500 & 2 & 0.6 & $\leq 100$ & 3.2 & 0.38 & 0.42 \\
2 & 1440 & 2 & 0.5 & $\leq 100$ & 2.7 & 0.47 & 0.46 \\
3 & 1565 & 2 & 0.65 & $\leq 100$ & 3.1 & 0.35 & 0.39 \\
4 & 1400 & 2 & 0.84 & $\leq 100$ & 1.9 & 0.51 & 0.54 \\
5 & 1400 & 2 & 0.6 & $200-250$ & 2.7 & 0.38 & 0.45 \\
6 & 1468 & 2.5 & 0.6 & $200-250$ & 3.7 & 0.46 & 0.47 \\
7 & 1505 & 2 & 0.6 & contact & 2.9 & 0.40 & 0.42 \\
\hline
\end{tabular}

* value between edge serrations

All strips are thicker than the rollers gap. As explained in part 3, this implies that the solid-liquid interfaces came in contact with each other before entering the nip region. That also means that the rolling ratio is important. Besides some folds and cracks appear on every strips and may be caused by the lack of ductility of the ternary alloy despite the small grain size. Some additional experiments of twin roller quenching on binary $\mathrm{Ni}_{50} \mathrm{Ti}_{50}$ alloys actually show that less cracks appear on binary $\mathrm{Ni}_{50} \mathrm{Ti}_{50}$ thin strips than on ternary $\mathrm{Ni}_{49.8} \mathrm{Ti}_{42.2} \mathrm{Hf}_{8}$ strips. As also mentioned in part 3, all foils are thicker on the edges than in the center ; that could be due to the difference of formability along the roll width, which is a result of temperature difference in the melt puddle [9].

Because of the numerous variables involved in the process, it is difficult to draw any conclusion from the comparison between the parameters of preparation and the variations of dimensions of the ribbons. The melt temperature is an important one which affects the width of the ribbons : the hotter the liquid is, the less viscous it is, the farther it laterally spreads. And actually ribbons 3 ( $T=1565), 1$ $(T=1500), 6(T=1468)$ are larger than ribbons 4, $5(T=1400)$. But some other factors like the feed rate and the rollers speed obviously influence the width and thickness of the foils.

\subsubsection{Thermal analysis}

DSC experiments were carried out to test the homogeneity of the ribbons along their length and along their width. Samples were carefully taken at the beginning of the ribbon (where the melt is first in contact with the rollers), in the middle and at the end (where the remnant liquid metal gets into the nip). In each case two samples were taken : one in the center of the width, the other at one of the edges.

Along the length of the foils, almost no difference of transformation temperatures has been noticed. The foils seem to be chemically and structurally homogeneous from the beginning to the end. Along the width, the transformation temperatures of the edges are usually higher than the transformation temperatures of the central area. Table 5 shows DSC results from all strips, samples being taken either from the edges or from the center. 
Table 5 : DSC results ( $2^{\text {nd }}$ cycle) for $\mathrm{Ni}_{49.8} \mathrm{Ti}_{42.2} \mathrm{Hf}_{8}$ strips in the as-quenched state

\begin{tabular}{lllllllllll}
\hline Ribbon & $\begin{array}{l}\mathrm{Mp} \\
\text { center } \\
\left({ }^{\circ} \mathrm{C}\right)\end{array}$ & $\begin{array}{l}\mathrm{Ap} \\
\text { center } \\
\left({ }^{\circ} \mathrm{C}\right)\end{array}$ & $\begin{array}{l}\Delta \mathrm{H}_{\mathrm{A} \rightarrow \mathrm{M}} \\
\text { center } \\
(\mathrm{J} / \mathrm{g})\end{array}$ & $\begin{array}{l}\Delta \mathrm{H}_{\mathrm{M} \rightarrow \mathrm{A}} \\
\text { center } \\
(\mathrm{J} / \mathrm{g})\end{array}$ & $\begin{array}{l}\mathrm{Ap}-\mathrm{Mp} \\
\text { center } \\
\left({ }^{\circ} \mathrm{C}\right)\end{array}$ & $\begin{array}{l}\mathrm{Mp} \text { edge } \\
\left({ }^{\circ} \mathrm{C}\right)\end{array}$ & $\begin{array}{l}\text { Ap edge } \\
\left({ }^{\circ} \mathrm{C}\right)\end{array}$ & $\begin{array}{l}\Delta \mathrm{H}_{\mathrm{A} \rightarrow \mathrm{M}} \\
\text { edge }(\mathrm{J} / \mathrm{g})\end{array}$ & $\begin{array}{l}\Delta \mathrm{H}_{\mathrm{M} \rightarrow \mathrm{A}} \\
\text { edge }(\mathrm{J} / \mathrm{g})\end{array}$ & $\begin{array}{l}\mathrm{Ap}-\mathrm{Mp} \\
\text { edge }\left({ }^{\circ} \mathrm{C}\right)\end{array}$ \\
\hline 1 & 90.3 & 158 & 28.9 & 28.2 & 67.7 & 97.5 & 161.8 & 28.8 & 28.9 & 64.3 \\
2 & 88.4 & 156.9 & 28.4 & 27.6 & 68.5 & 98 & 163.4 & 29.1 & 28.9 & 65.4 \\
3 & 65.2 & 133.2 & 25.3 & 26.9 & 68 & 72.4 & 143.1 & 29.3 & 28.6 & 70.7 \\
4 & 93.4 & 164.7 & 28.1 & 28.5 & 71.3 & 96.7 & 164.6 & 28 & 28.6 & 67.9 \\
5 & 82.8 & 147.4 & 27.4 & 25.8 & 64.6 & 92.4 & 158.9 & 29.4 & 28.9 & 66.5 \\
6 & 94.6 & 159.6 & 28.7 & 28.5 & 65 & 99.5 & 162.4 & & 29.4 & 62.9 \\
7 & 61.3 & 129.2 & 25.1 & 24.9 & 67.9 & 79.8 & 150.8 & 26.1 & 26.2 & 71 \\
\hline
\end{tabular}

We can first notice that transformation temperatures of the edges are higher than in the center, as mentionned before. Strip 4 is the most homogeneous, which is not surprising since its width is the smallest. Strip 7 exhibits the most important difference between center and edges $\left(20^{\circ} \mathrm{C}\right)$. This difference of transformation temperatures is due to some variations of grain size along the width of the ribbons : by optical microscopy, we can see that grains are smaller in the center than at the edges. As the melt spreads laterally along the rollers from the impact area of the jet, the contact length varies along the distance [5]. Indeed it decreases as the flow moves away from the center. Moreover thermal transfer is not identical as the melt flows in the same direction as the substrate and as it moves perpendicularly. And subsequently, cooling is less efficient in the border areas than in the center of the samples.

Finally all foils do not have the same transformation temperatures. Strips 1, 2, 4 and 6 have similar temperatures which are as high as the transformation temperatures of the $\mathrm{Ni}_{49.8} \mathrm{Ti}_{42.2} \mathrm{Hf}_{8}$ bulk material. Strip 5 has slighty lower temperatures and strips 3 and 7 have about $20^{\circ} \mathrm{C}$ lower temperatures. Work is currently in progress to explain the existence of such differences.

\section{CONCLUSIONS}

The twin roll casting technique is promising for production of copper based shape memory material as it is an unique one-step forming process which eliminates or restrictes the need for working. Moreover, it allows to consider high temperature applications as high transformation temperatures are maintained.

Presented twin roll quenching experiments on $\mathrm{Ni}_{49.8} \mathrm{Ti}_{42.2} \mathrm{Hf}_{8}$ alloy are first investigations : twin roll quenching avoids difficult rolling schedule but the strips we obtained still exhibit some cracks ; transformation temperatures are not always high, probably depending on the preparation parameters. Thus it is necessary to carry on with new experiments where the solidification end point would be right into the nip, which would probably decrease the rolling ratio and maybe improve the strips qualities.

\section{References}

1. E. Babic, E. Girt, R. Kresnik and B. Leontic, J. Phys. 3 (1970) 1014

2. H.S. Chen, C.E. Miller, Rev. Sci. Instrum. 41 (1970) 1237

3. A.W. Cramb, in Proceedings of Melt Spinning, Strip Casting and Slab Casting, Edts. E.F. Matthys and W.G. Truckner - The Minerals, Metals and Materials Soc. (1996) p. 1-11

4. J.T. Choi, Y.H. Kim, C.H. Choi, K.H. Ho and H.Y. Ra, in Proc. of Melt Spinning, Strip Casting and Slab Casting, Edts. E.F. Matthys and W.G. Truckner - TMS (1996) p. $43-52$

5. V. Reszetko-Orlionnet and J. Bigot, Proc. of Melt Spinning and Strip Casting : research and implementation, San Diego, March 1992, Edt. E.F. Matthys - TMS annual meeting p. 201-211

6. INCO-Copernicus Project IC15-CT96-0704 Final Report (1999)

7. Y.V. Murty, R.P.I. Adler, J. of Materials Sci., 17 (1982) p. 1945-1954

8. C.G. Kang, Y.D. Kim and S.W. Lee, Proc. of Melt Spinning, Strip Casting and Slab Casting, Edts. E.F. Matthys and W.G. Truckner - TMS (1996) p. 65-86

9. J. Ishiara, I. Ikuta, Proc. of 4th Int. Conf. On Rapidly Quenched Metals, Sendai, 1981 p. 19 